\title{
Comprehensive care programme for patients with chronic obstructive pulmonary disease: a randomised controlled trial
}

\author{
Fanny W S Ko, ${ }^{1}$ N K Cheung, ${ }^{2}$ Timothy H Rainer, ${ }^{2}$ Christopher Lum, ${ }^{3}$ Ivor Wong, ${ }^{4}$ \\ David S C Hui ${ }^{1}$
}

- Additional material is published online only. To view please visit the journal online (http://dx.doi.org/10.1136/ thoraxjnl-2016-208396)

${ }^{1}$ Division of Respiratory Medicine, Department of Medicine and Therapeutics, The Chinese University of Hong Kong, Shatin, New Territories, Hong Kong

${ }^{2}$ Accident and Emergency Department, The Chinese University of Hong Kong, Hong Kong, Hong Kong ${ }^{3}$ Department of Medicine, Shatin Hospital, Hong Kong Hong Kong

${ }^{4}$ Physiotherapy Department, Prince of Wales Hospital, Hong Kong, Hong Kong

\section{Correspondence to} Professor David S C Hui, Department of Medicine and Therapeutics, The Chinese University of Hong Kong. Prince of Wales Hospital, 30-32 Ngan Shing Street, Shatin, New Territories, Hong Kong;

dschui@cuhk.edu.hk

Received 25 January 2016 Revised 9 May 2016 Accepted 13 June 2016 Published Online First 28 July 2016

\section{ABSTRACT}

Background There have been no randomised controlled trials that specifically evaluate the effect of a comprehensive programme with multidisciplinary input on patients who have just been discharged from hospital after treatment of acute exacerbation of COPD (AECOPD). The aim of this study was to assess whether a comprehensive care programme would decrease hospital readmissions and length of hospital stay (LOS) for patients with COPD.

Methods Patients discharged from hospital after an episode of AECOPD were randomised to an intervention group (IG) or usual care group (UG). The IG received a comprehensive, individualised care plan which included education from a respiratory nurse, physiotherapist support for pulmonary rehabilitation, 3-monthly telephone calls by a respiratory nurse over 1 year, and follow-up at a respiratory clinic with a respiratory specialist once every 3 months for 1 year. The UG were managed according to standard practice. The primary outcome was hospital readmission rate at 12 months. Results 180 patients were recruited (IG, N=90; UG, $\mathrm{N}=90$; mean $\pm \mathrm{SD}$ age $74.7 \pm 8.2$ years, $172(95.6 \%)$ men; mean \pm SD FEV $145.4 \pm 16.6 \%$ predicted). At 12 months, the adjusted relative risk of readmission was $0.668(95 \% \mathrm{Cl} 0.449$ to $0.995, \mathrm{p}=0.047)$ for the IG compared with the UG. At 12 months, the IG had a shorter LOS $(4.59 \pm 7.16$ vs $8.86 \pm 10.24$ days, $p \leq 0.001)$ greater improvement in mean Modified Medical Research Council Dyspnoea Scale $(-0.1 \pm 0.6$ vs $0.2 \pm 0.6$, $\mathrm{p}=0.003$ ) and St George's Respiratory Questionnaire score $(-6.9 \pm 15.3$ vs $-0.1 \pm 13.8, p=0.003)$ compared with the UG.

Conclusions A comprehensive COPD programme can reduce hospital readmissions for COPD and LOS, in addition to improving symptoms and quality of life of the patients.

Trial registration number NCT 01108835, Results.

\section{INTRODUCTION}

COPD is a common disease worldwide ${ }^{1-3}$ with significant morbidity, which incurs heavy use of healthcare resources. The prevalence of COPD varied from $11.4 \%$ to $26.1 \%$ in a multi-city study that surveyed the population with spirometry. ${ }^{1}$ In 2005, COPD ranked second in respiratory causes for hospitalisation and inpatient bed days in Hong Kong. ${ }^{4}$ In people $>75$ years of age, the hospitalisation rate for COPD was as high as $2225 / 100000 .^{4}$

\section{Key messages}

What is the key question?

- There have been no randomised controlled trials that specifically evaluate the effect of a comprehensive programme with multidisciplinary input on patients who have just been discharged from hospital after treatment of acute exacerbation of COPD (AECOPD), although there are some data suggesting that a post-AECOPD rehabilitation programme and self-management can help to decrease exacerbations and improve the quality of life of such patients.

What is the bottom line?

- A comprehensive COPD programme for patients just discharged for an episode of AECOPD can reduce hospital readmissions for COPD and length of hospital stay, in addition to improving symptoms and quality of life of the patients.

\section{Why read on?}

- AECOPD incurs significant morbidity. For high-risk patients admitted for AECOPD, it is important to look for ways of decreasing recurrent admissions.

The cost of hospital admissions is substantial and is the single largest source of expenditure on patients with COPD. ${ }^{5}$ Previous studies ${ }^{6} 7$ have shown that pulmonary function and quality of life (QOL) are adversely affected by frequent exacerbations of COPD. It is thus important to develop strategies to prevent acute exacerbation of COPD (AECOPD) in order to improve QOL and reduce the economic burden of this group of patients to society.

Considerable efforts have been made by investigators to evaluate if various management programmes for patients with COPD can improve their QOL and reduce their hospital readmissions in different countries. These interventions, including nurse-administered home care for AECOPD, ${ }^{8-10}$ disease-specific self-management plans, ${ }^{11}{ }^{12}$ implementation of the chronic care model, ${ }^{13}$ and home visits by respiratory health workers, ${ }^{14-16}$ have had variable degrees of success. A recent meta-analysis of 26 trials with different programme designs in various healthcare settings, and with a follow-up
Cheung NK, Rainer $\mathrm{TH}_{\text {, }}$

et al. Thorax 2017;72:122-

128 
period of between 3 and 24 months, has suggested that integrated disease-management programmes improved diseasespecific QOL and exercise capacity, in addition to reducing hospital admissions and hospital days per person. ${ }^{17}$ To the best of our knowledge, there has been no randomised controlled trial (RCT) that specifically evaluates the effects of a comprehensive programme with multidisciplinary input on patients who have just been discharged from hospital after treatment of AECOPD, although there are data suggesting that a post-AECOPD rehabilitation programme and self-management can help to decrease exacerbations and improve the QOL of such patients. ${ }^{18}{ }^{19} \mathrm{We}$ have recently reported that patients who had undergone a 16-week comprehensive COPD care programme had fewer hospital admissions 1 year after the programme compared with 1 year before the programme. ${ }^{20}$ We now report the results from an RCT to assess if a comprehensive programme consisting of multidisciplinary inputs from doctors, respiratory nurses and physiotherapists that provided an individualised care plan for each subject would decrease the readmission rate of patients with COPD who had just been discharged from hospital after treatment for an episode of AECOPD.

\section{METHODS}

Patients who had been admitted with AECOPD to the Prince of Wales Hospital, a tertiary university-affiliated hospital, were screened for this study. The recruitment period was from June 2010 to June 2012. AECOPD was defined when a patient with background $\mathrm{COPD}^{3}$ presented with at least two major symptoms (increased dyspnoea, increased sputum purulence, increased sputum volume) or one major and one minor symptom (nasal discharge/congestion, wheeze, sore throat, cough) for at least two consecutive days. ${ }^{6}{ }^{21}$ Exclusion criteria were: age <40 years; a diagnosis of asthma; chronic lung diseases other than COPD (eg, pneumoconiosis, pulmonary fibrosis); very severe medical illness that would affect the patient's ability to participate in this study (eg, terminal malignancy); and unable to give informed consent. Patients were invited to return to our research clinic for baseline assessment at about 3-4 weeks after hospital discharge. The Joint Chinese University of Hong Kong-New Territories East Cluster Clinical Research Ethics Committee approved the study (CREC 2008.442-T). The study was registered at ClinicalTrias.gov (NCT 01108835). Informed written consent was obtained from each subject.

Patients were randomised to either an intervention group (IG) or a control group (usual care group (UG)).

\section{Intervention group}

\section{Baseline}

Patients were interviewed by a respiratory nurse and given education in two 1-hour sessions (individual education sessions including anatomy and physiology of the respiratory system, pathophysiology of COPD, smoking cessation, technique of using medications, dyspnoea management, nutrition, selfmanagement and exacerbation-reduction skills, coping with psychological distress and relaxation techniques, social and community support, and, if appropriate, knowledge on long-term oxygen therapy). All patients were also assessed by a physiotherapist who educated them on exercise benefits and strategies, breathing and sputum-removal techniques, and energyconservation techniques. The physiotherapist provided every patient with an individualised physical training programme to perform at home or a short course of outpatient pulmonary rehabilitation (PR). The patients were assessed by a respiratory physician who adjusted their medications and also managed their COPD according to international guidelines. ${ }^{3}$ In addition, patients were provided with a telephone number which they could call to seek advice from our respiratory nurse during office hours if there was any concern about their disease. After office hours, questions were recorded on the answering machine and a return phone call was made by the nurse the next working day. Arrangements could be made for a patient to see a respiratory physician as an outpatient if necessary.

\section{Subsequent intervention}

Patients received 3-monthly telephone calls from a respiratory nurse for a period of 1 year to assess their condition and to answer any queries. Patients were also followed-up in the respiratory research clinic by a respiratory specialist once every 3 months for 1 year.

More details of the interventions are available in the online supplemental file.

\section{Usual care group}

The control group was managed with the usual care. The attending physician determined the patient's medication and follow-up as per normal practice (eg, continued follow-up by the patient's original doctor/clinic appointment), and underwent baseline assessment and a 12-month assessment.

\section{Randomisation}

The randomisation method is shown in the online supplementary file.

\section{Assessments}

The assessment plan was the same for the intervention and the control group. Demographic data on the patients were collected at baseline. Lung function (pre- and post-bronchodilator) was determined according to the American Thoracic Society (ATS) and European Respiratory Society (ERS) standards. ${ }^{22}$ The updated predicted spirometry values for Hong Kong Chinese was used to calculate the predicted lung function. ${ }^{23}$ The Modified Medical Research Council Dyspnoea Scale (MMRC), ${ }^{24}$ 6 min walk test ${ }^{25}$ and St George's Respiratory Questionnaire $(\mathrm{SGRQ})^{26}$ were conducted at baseline and 12 months.

Subsequent hospital admissions and mortality were recorded after the baseline assessment over a period of 12 months. Exacerbations that required treatment with a course of oral steroids or antibiotics, Accident and Emergency Department visits, and hospitalisations were recorded. The information was obtained from the patients with verification from their medical records. Immediate family members were contacted by phone to check if the patient did not return for follow-up to see if they had died.

Owing to the nature of the intervention, this was an open study for the patients and therapists, but the research assistant performing the lung function, walking tests and questionnaire tests was neither involved in the delivery of patient care nor aware of the randomisation process.

\section{Outcomes}

The primary end point was the hospital readmission rate at 1 year. The secondary end points were QOL, mortality, lung function, and exercise capacity at 1 year.

\section{Statistical analysis}

Details of sample size calculation are shown in the online supplementary file. Data were analysed by SPSS V.21.0. Analyses were conducted according to the intention-to-treat principle. Hospital 
readmissions are presented as the incident rate (mean readmissions per person year). Negative binomial regression was used to compare the relative risk (RR) of readmissions between groups with adjustment of baseline characteristics (age, gender, length of hospital stay on the recruitment admission, 6 min walk test, postbronchodilator $\mathrm{FEV}_{1} \%$ predicted and number of exacerbations in the 12 months before recruitment). Comparisons of the differences at baseline and 12 months between intervention and control groups on hospital readmissions, QOL, lung function and exercise capacities were performed using the Mann-Whitney $\mathrm{U}$ test. The baseline values of subjects who died before the 12-month end point or refused to return for follow-up were carried forward for the analyses. Survival analysis was performed using the Cox proportional-hazards model and log rank test. Data are presented as mean $\pm S D$, number (\%) or median (IQR), and $\mathrm{p}<0.05$ was considered significant.

\section{RESULTS}

Altogether 180 subjects fulfilled the inclusion criteria and were randomised for this study. Figure 1 shows the flow of the patients. Ninety subjects were randomised to the IG and 90 to the UG. At 12 months, 73 and 69 subjects returned for assessment in our research clinic. Ten and 12 subjects in the IG and UG, respectively, had died at 12 months.

The demographic data of the patients are shown in table 1 . There was no difference in the demographic characteristics between the IG and UG. The mean \pm SD $\mathrm{FEV}_{1} \%$ predicted of the IG and UG were $46.7 \pm 18.3$ and $44.2 \pm 14.7 \%(p=0.324)$, respectively, and most subjects had global obstructive lung disease $(\mathrm{GOLD})^{3}$ stage II or III lung function by spirometry. In the IG, only 64 subjects $(71.1 \%)$ attended the physiotherapy sessions, and the mean number of sessions for those who

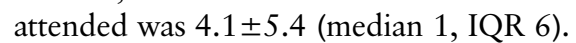

Readmission of the subjects presented as the incidence rate (mean readmissions per person time) and length of hospital stay of the patients at 12 month follow-up are shown in table 2 .
In the IG, $22(24.4 \%), 10(11.1 \%)$ and $12(13.3 \%)$ patients had been readmitted for AECOPD 1, 2 and 3 times, respectively, at 12 months, while for the UG, 20 (22.2\%), 18 (20\%) and $25(27.8 \%)$ had been readmitted 1,2 and 3 times, respectively, at 12 months. At 12 months, the IG had a lower RR of readmission and shorter length of hospital stay for AECOPD than the UG. The incident rate for readmission for the IG and UG were 1.24 and 1.85 , respectively, with an adjusted RR of readmission of $0.668(95 \%$ CI 0.449 to $0.995, \mathrm{p}=0.047)$ for the IG compared with the UG (the unadjusted RR of readmission was 0.651 (95\% CI 0.442 to $0.959, \mathrm{p}=0.030)$ ). A Kaplan-Meier plot of the patients' first readmission for AECOPD is shown in figure 2. Subjects in the IG had a significantly longer period of time between readmission and recruitment than those in the UG ( $p$ value of log-rank test $=0.003$ ). Using the Cox proportionalhazards model, we found the HR of readmission for AECOPD of the IG compared with the UG to be 0.565 (95\% CI 0.384 to $0.832, \mathrm{p}=0.004)$.

Many patients had their medications adjusted in subsequent doctors' consultations during the study period. We retrieved the medications that the patients were taking during the last follow-up (at 12 month follow-up; for those patients who had died or defaulted follow-up, we took data from the last follow-up in the study period). In the IG, 63 (70.0\%) subjects were on long-acting $\beta$ agonist (LABA) at the last follow-up. When subjects on LABA at the end of the study were compared with those not on LABA, the adjusted RR of readmission for AECOPD at 12 months was 1.284 (95\% CI 0.602 to 2.741 , $\mathrm{p}=0.518$ ). Concerning long-acting antimuscarinic antagonist (LAMA) use, $64(71.1 \%)$ subjects were on LAMA at the last follow-up in the IG. Those subjects who were on LAMA at the end of the study had an adjusted RR for readmission of 0.803 (95\% CI 0.412 to $1.566, \mathrm{p}=0.520$ ) in comparison with patients not taking LAMA in the IG.

For all the subjects in the IG, if they could not return for supervised physiotherapy, they were advised to follow a home

Figure 1 Flow of the subjects.

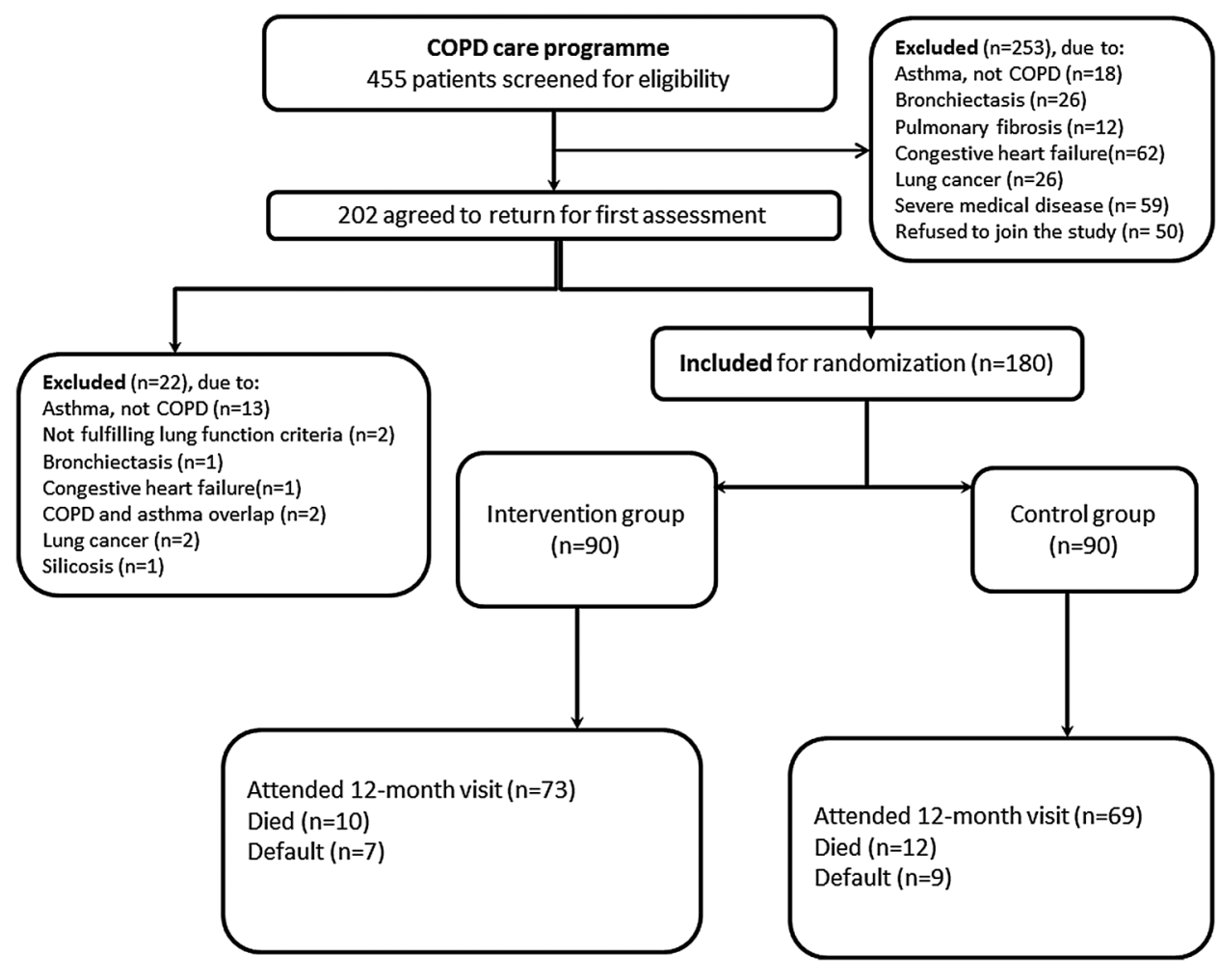


Table 1 Demographic characteristics of patients

\begin{tabular}{|c|c|c|}
\hline Characteristic & $\begin{array}{l}\text { Intervention } \\
\text { group } \\
(n=90)\end{array}$ & $\begin{array}{l}\text { Usual care } \\
\text { group } \\
(n=90)\end{array}$ \\
\hline Age (years) & $74.9 \pm 7.9$ & $74.6 \pm 8.6$ \\
\hline Gender (male) & $85(94.4)$ & $87(96.7)$ \\
\hline Body mass index $\left(\mathrm{kg} / \mathrm{m}^{2}\right)$ & $20.97 \pm 3.87$ & $21.36 \pm 4.34$ \\
\hline \multicolumn{3}{|l|}{ Spirometry (post-bronchodilator) } \\
\hline $\mathrm{FEV}_{1}(\mathrm{~L})$ & $0.96 \pm 0.38$ & $0.92 \pm 0.35$ \\
\hline FVC (L) & $2.02 \pm 0.63$ & $1.98 \pm 0.62$ \\
\hline $\mathrm{FEV}_{1} \%$ predicted normal & $46.7 \pm 18.3$ & $44.2 \pm 14.7$ \\
\hline FVC \% predicted normal & $70.5 \pm 19.6$ & $68.7 \pm 16.9$ \\
\hline $\mathrm{FEV}_{1} / \mathrm{FVC}$ ratio & $47.4 \pm 11.3$ & $46.9 \pm 11.6$ \\
\hline \multicolumn{3}{|l|}{ GOLD stage } \\
\hline 1 & $1(1.1)$ & $2(2.2)$ \\
\hline II & $36(40)$ & $28(31.1)$ \\
\hline III & $36(40)$ & $45(50)$ \\
\hline IV & $17(18.9)$ & $15(16.7)$ \\
\hline 6 min walk test $(m)$ & $282 \pm 106$ & $263 \pm 103$ \\
\hline \multicolumn{3}{|l|}{ St George's Questionnaire } \\
\hline Symptoms & $55.9 \pm 19.6$ & $59.9 \pm 19.8$ \\
\hline Activities & $59.3 \pm 25.4$ & $55.2 \pm 27.2$ \\
\hline Impacts & $36.8 \pm 21.1$ & $36.7 \pm 20.8$ \\
\hline Total & $46.8 \pm 20.2$ & $46.2 \pm 19.8$ \\
\hline $\begin{array}{l}\text { Number of exacerbations in the past } \\
12 \text { months }\end{array}$ & $1.03 \pm 1.67$ & $1.38 \pm 1.58$ \\
\hline Flu vaccination in the past 12 months & $46(51.1)$ & $49(54.4)$ \\
\hline On long-term home oxygen & $8(8.9)$ & $12(13.3)$ \\
\hline \multicolumn{3}{|l|}{ Smoking status } \\
\hline Current smokers & $13(14.4)$ & $22(24.4)$ \\
\hline Ex-smokers & 77 (85.6) & $68(75.6)$ \\
\hline Pack-years & $47.5 \pm 27.1$ & $53 \pm 28.9$ \\
\hline Charlson Index & $1.5 \pm 0.8$ & $1.6 \pm 0.8$ \\
\hline MMRC & $2 \pm 0.8$ & $2.1 \pm 0.8$ \\
\hline \multicolumn{3}{|l|}{ Medications } \\
\hline LABA & $22(24.4)$ & $21(23.3)$ \\
\hline LAMA & $6(6.7)$ & $5(5.6)$ \\
\hline ICS & $63(70)$ & $63(70)$ \\
\hline Theophylline & $23(25.6)$ & $25(27.8)$ \\
\hline \multicolumn{3}{|l|}{ Comorbidity } \\
\hline Hypertension & $31(34.4)$ & $37(41.1)$ \\
\hline Diabetes mellitus & $6(6.7)$ & $14(15.6)$ \\
\hline Hyperlipidaemia & $7(7.8)$ & $13(14.4)$ \\
\hline Ischaemic heart disease & $9(10.0)$ & $8(8.9)$ \\
\hline Heart failure & $8(8.9)$ & $7(7.8)$ \\
\hline Old pulmonary TB & $14(15.6)$ & $15(16.7)$ \\
\hline
\end{tabular}

Data are presented as mean \pm SD or number (\%).

GOLD, global obstructive lung disease; ICS, inhaled corticosteroid; LABA, long-acting $\beta$-agonist; LAMA, long-acting muscarinic antagonist (anticholinergic agent); MMRC, Modified Medical Research Council Dyspnoea Scale.

exercise programme (see the online supplementary file for the training details). If we consider those who returned at least four times (mean number of attendances for those who returned for training) for physiotherapy to have some form of supervised outpatient PR, there was no difference in the adjusted RR of readmissions for AECOPD in those with supervised outpatient physiotherapy $(\mathrm{n}=30)$ versus those with home exercise $(\mathrm{n}=60)$ (adjusted RR 0.562 (95\% CI 0.273 to $1.156, \mathrm{p}=0.117$ ).

The changes in lung function, 6 min walk test, MMRC score and SGRQ score at the 12 month follow-up from baseline for the subjects are shown in table 3 . There was not much improvement compared with baseline in lung function in either the IG or UG at 12 months, and the two groups did not show any significant difference in the change in lung function at 12 months compared with baseline. The same was observed for the $6 \mathrm{~min}$ walk test (difference $-10.0 \pm 61.2$ in IG vs $-22.5 \pm 71.4 \mathrm{~m}$ in UG, $p=0.233$ ). There was an improvement in MMRC score at 12 months when comparing the IG against the UG $(-0.1 \pm 0.6$ vs $0.2 \pm 0.6, p=0.003)$. On the SGRQ score, there was improvement in the symptoms domain $(-10.2 \pm 22.5$ vs $-3.2 \pm 21.3$, $\mathrm{p}=0.045)$, activity domain $(-6.2 \pm 18.0$ vs $3.6 \pm 19.4, \mathrm{p} \leq 0.001)$ and total score $(-6.9 \pm 15.3$ vs $-0.1 \pm 13.8, \mathrm{p}=0.003)$ at 12 months compared with baseline but not for the impacts domain $(-6.2 \pm 17.4$ vs $-1.1 \pm 16.6, \mathrm{p}=0.075)$. There was also no change in the smoking prevalence in the IG at baseline and 12 months.

\section{DISCUSSION}

This RCT has shown that, in a group of patients who were recently admitted for AECOPD, a comprehensive, individualised care plan could decrease the hospital readmission rate and length of hospital stay at 1 year follow-up compared with subjects treated with the usual care. In addition, the dyspnoea score, MMRC, was improved at 12 months in the IG compared with the UG. Furthermore, the QOL of the subjects at 12 months improved and the total SGRQ score in the IG had a mean improvement of -6.9 points, which is higher than the 4-point cut-off for minimal clinical signficance. ${ }^{27}$

Our respiratory nurses provided COPD education and 3-monthly phone calls to the patients to answer their queries and check their health status. We had offered some selfmanagement skills to the patients including how to use the medication and how to cope with symptoms, dyspnoea and psychological distress. However, we did not provide any written action plan or crisis pack such as oral steroids and antibiotics for self-treatment of exacerbations. A recent Cochrane Review found that self-management interventions (in the absence of supervised and effective exercise) in patients with COPD were associated with improved health-related $\mathrm{QOL}$ as measured by the SGRQ, a reduction in respiratory-related and all-cause hospital admissions, and improvement in dyspnoea as measured by the MMRC. However, heterogeneity among interventions, study populations, follow-up time and outcome measures makes it difficult to formulate clear recommendations regarding the most effective form and content of self-management in COPD. ${ }^{19}$ In this Cochrane Review, only one ${ }^{28}$ among the 23 studies involved patients immediately after an AECOPD. Another systematic review that examined the effects of selfmanagement alone delivered during hospitalisation for an AECOPD or within 1 month of hospital discharge found no effects on mortality rate, depressive symptoms, primary care usage or exercise capacity. Minimal effects were found on selfefficacy, anxiety symptoms, and health-promoting behaviour. ${ }^{29}$

One of the components of our programme involved physiotherapist support for PR. A Cochrane Review of nine heterogeneous trials of peri- and early post-hospitalisation PR showed wide-ranging benefits, including a significantly reduced risk of readmission. ${ }^{30}$ The results of that review have led to strong recommendations by the National Institute for Health and Care Excellence (NICE), ${ }^{31}$ the British Thoracic Society ${ }^{32}$ and ATS-ERS $^{32}$ for post-exacerbation rehabilitation. Our previous study showed that an early rehabilitation programme for 8 weeks after AECOPD led to improvement in QOL up to 6 months, but did not reduce healthcare utilisation at 1 year. ${ }^{18}$ In the present study, although we had offered the rehabilitation 
Table 2 Readmissions and length of stay of subjects at 12 months

\begin{tabular}{|c|c|c|c|}
\hline & $\begin{array}{l}\text { Intervention group } \\
(n=90)\end{array}$ & $\begin{array}{l}\text { Usual care group } \\
(n=90)\end{array}$ & p Value \\
\hline Crude rate of readmissions for COPD exacerbations (number of times per person-year) & 1.24 & 1.85 & \\
\hline Adjusted relative risk of readmission for COPD $(95 \% \mathrm{CI}) \dagger$ & $0.668(0.449$ to 0.995$)$ & 1 & $0.047^{*}$ \\
\hline Length of stay in hospital for COPD exacerbations (days) $\ddagger$ & $4.59 \pm 7.16$ & $8.86 \pm 10.24$ & $<0.001$ * \\
\hline Crude rate of readmissions for all causes (number of times per person-year) & 1.75 & 2.59 & \\
\hline Adjusted relative risk of readmissions for all causes $(95 \% \mathrm{Cl}) \dagger$ & $0.682(0.471$ to 0.987$)$ & 1 & $0.042^{*}$ \\
\hline Length of stay in hospital for all causes (days) $\ddagger$ & $7.41 \pm 11.29$ & $12.21 \pm 12.87$ & $<0.001^{*}$ \\
\hline
\end{tabular}

programme to the patients (which formally consisted of 2 hours of training twice a week over 8 weeks), only $71.1 \%$ of the subjects attended at least one session and the mean number of sessions attended was 4.1 for the attendees. A recent observational study reported that only $9 \%$ of people completed a posthospitalisation PR programme over a 6 -month period. ${ }^{34}$ From the patient perspective, a common reason cited for nonparticipation in PR was transport arrangement, particularly just after discharge when patients often reported feeling too ill and/ or breathless to engage. ${ }^{35}$ As guidelines ${ }^{36}$ suggest that 20 sessions of exercise training are needed to be effective, we are not sure about the effect of the exercise component in this multidisciplinary programme in decreasing readmissions and length of hospital stay related to AECOPD.

These patients were also seen by respiratory physicians, and the COPD medications were adjusted according to the GOLD guideline. $^{3}$ Since many patients were not on LABA and LAMA before joining the programme, optimisation of drug treatment might have played an important role in decreasing readmissions for AECOPD. A previous study has shown that tiotropium, in comparison with placebo, could provide benefit with sustained improvement in lung function, reductions in exacerbations and risk of exacerbation-related hospitalisations, and improvement in health status. ${ }^{37}$ About $50 \%$ of our patients were not taking

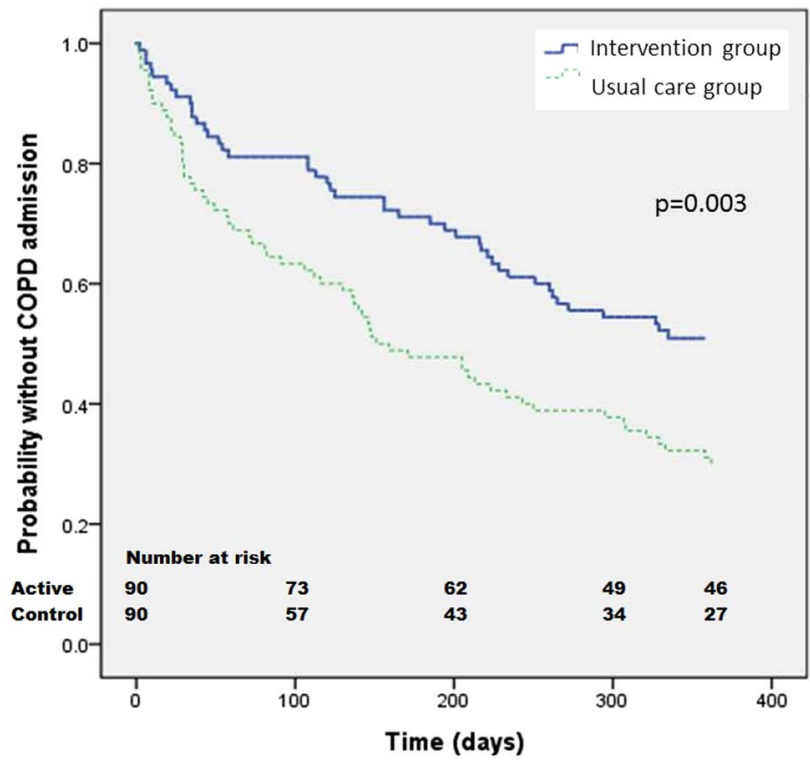

Figure 2 Kaplan-Meier curve of the first readmission for acute exacerbation of COPD in the intervention and control groups.
LABA at the baseline visit. A previous large-scale study has shown that a combination of LABA and inhaled corticosteroid (ICS) could decrease COPD exacerbations, but not mortality. ${ }^{38}$

It is interesting to note that not all integrated COPD care programmes are effective. A recent multicentre, pragmatic cluster RCT in the Netherlands found that an integrated disease management approach delivered in the primary care setting led to no additional benefit compared with usual care in terms of QOL and COPD exacerbation rates of the patients when evaluated at 24 months. ${ }^{39}$ Another study even found that a comprehensive care management programme could not decrease COPD-related hospitalisations and the trial was terminated prematurely because of the unanticipated excess mortality in the active arm. ${ }^{40} \mathrm{~A}$ recent study found that a predischarge bundle intervention in AECOPD was not sufficient to reduce the 30-day risk of hospitalisations or emergency department visits. ${ }^{41}$ Every intervention programme thus should have its effectiveness and safety tested, as different combinations of services may have different effects. In this trial, the mortality rate was similar between the PR and control group $(11.1 \%$ vs $13.3 \%)$.

Direct comparisons between the usual care offered by Hong Kong and the UK would be difficult. In general, Hong Kong follows the GOLD guideline, ${ }^{3}$ whereas the UK uses the NICE ${ }^{42}$

Table 3 Change in lung function, 6 min walk test, MMRC score and SGRQ score at the 12 month follow-up compared with baseline

\begin{tabular}{|c|c|c|c|}
\hline & $\begin{array}{l}\text { Intervention } \\
\text { groupt }(n=90)\end{array}$ & $\begin{array}{l}\text { Usual care } \\
\text { groupt }(n=90)\end{array}$ & $\mathrm{p}$ Value \\
\hline \multicolumn{4}{|c|}{ Spirometry (post-bronchodilator) } \\
\hline $\mathrm{FEV}_{1} \%$ predicted normal & $0.8 \pm 6.8$ & $-0.4 \pm 7.4$ & 0.265 \\
\hline FVC $\%$ predicted normal & $-2.4 \pm 13.3$ & $-3.1 \pm 10.2$ & 0.628 \\
\hline $\mathrm{FEV}_{1} / \mathrm{FVC}$ ratio & $2.2 \pm 8.9$ & $1.3 \pm 6.8$ & 0.653 \\
\hline 6 min walk test (m) & $-10.0 \pm 61.2$ & $-22.5 \pm 71.4$ & 0.233 \\
\hline MMRC score & $-0.1 \pm 0.6$ & $0.2 \pm 0.6$ & $0.003^{*}$ \\
\hline \multicolumn{4}{|l|}{ SGRQ } \\
\hline Symptoms & $-10.2 \pm 22.5$ & $-3.2 \pm 21.3$ & $0.045^{*}$ \\
\hline Activities & $-6.2 \pm 18.0$ & $3.6 \pm 19.4$ & $<0.001^{*}$ \\
\hline Impacts & $-6.2 \pm 17.4$ & $-1.1 \pm 16.6$ & 0.075 \\
\hline Total & $-6.9 \pm 15.3$ & $-0.1 \pm 13.8$ & $0.003^{*}$ \\
\hline \multicolumn{4}{|c|}{$\begin{array}{l}\text { Data are presented as mean } \pm S D \text {. } \\
{ }^{*} p<0.05 \text {.Data are mean. } \\
+ \text { The data presented are the change, calculated by taking the baseline value from the } \\
12 \text { month value. } \\
\text { MMRC, Modified Medical Research Council Dyspnoea Scale; SGRQ, St George's } \\
\text { Respiratory Questionnaire. }\end{array}$} \\
\hline
\end{tabular}

Ko FWS, et al. Thorax 2017;72:122-128. doi:10.1136/thoraxjnl-2016-208396 
and the British Thoracic Society guidelines ${ }^{32}$ for COPD care and PR. There is generally good agreement on treatment goals, criteria for diagnosis of COPD, and use of long-acting bronchodilators as the cornerstone of treatment among guidelines for COPD management, but the compliance with guidelines is low. For example, in Hong Kong, overall, long-acting bronchodilators and PR were offered to $16 \%$ and 5\%, respectively, of those who had met the recommendations of the GOLD guidelines. ${ }^{43}$ In the UK, COPD is not treated according to GOLD ${ }^{3}$ and NICE recommendations ${ }^{42}$ in the primary-care setting. Some patients receive no treatment despite experiencing symptoms. Among those on treatment, most receive ICS irrespective of the severity of airflow limitation, asthma diagnosis, and exacerbation history. Many patients on treatment continue to have symptoms. ${ }^{44}$

One major limitation of this study is that it was a single tertiary centre study and involved patients with severe COPD who had just experienced an episode of AECOPD. It is uncertain if this comprehensive programme would be effective in other healthcare settings. As this was a multicomponent study, it would be difficult to assess which component had contributed more to the decrease in readmissions for AECOPD. There was no improvement in pulmonary function and 6 minute walk distance (MWD) when we compared the IG and UG. In the IG, those on LABA or LAMA appeared to have no decrease in readmissions over those not on these drugs. A multicomponent intervention was effective in decreasing readmissions for AECOPD and the reasons were not clear. Our subjects were predominantly male (over 90\%). A previous study from Canada, which retrospectively reviewed data of patients admitted for AECOPD for the impact of a comprehensive and individualised care management strategy, found a reduction in 90-day readmission rate for AECOPD only in women, and not in men or the whole group. ${ }^{45}$ Male and female patients with COPD might have different responses to multidisciplinary intervention and we were unable to assess the gender difference in our study as there were too few women. The interventions might be different among our patients in the IG. For example, physiotherapy was offered to the patients, but not every patient attended the sessions. Furthermore, we only followed-up our patients for 1 year; it is uncertain if the effect of this programme can be maintained beyond the follow-up period. Finally, costeffectiveness was not assessed in this study.

In conclusion, this RCT has shown that a comprehensive, individualised care plan can decrease hospital readmissions and length of hospital stay over 1 year in patients who were recently admitted for AECOPD, compared with usual care. Further studies are needed to test which component(s) would contribute more to the desired outcomes and to assess the costeffectiveness of such programmes for patients with COPD.

Contributors FWSK, THR and DSCH designed the study. FWSK, NKC, THR, CL and DSCH recruited the subjects and supervised the study. FWSK assessed the patients in the doctor's clinic. IW arranged and supervised the physiotherapy for the patients. FWSK and DSCH analysed the data. All authors contributed to writing of the manuscript.

\section{Competing interests None declared.}

Ethics approval The Joint Chinese University of Hong Kong-New Territories East Cluster Clinical Research Ethics Committee (CREC 2008.442-T).

Provenance and peer review Not commissioned; externally peer reviewed.

\section{REFERENCES}

1 Buist AS, McBurnie MA, Vollmer WM, et al. International variation in the prevalence of COPD (the BOLD Study): a population-based prevalence study. Lancet 2007;370:741-50.
2 Ko FW, Hui DS, Lai CK. Worldwide burden of COPD in high- and low-income countries. Part III. Asia-Pacific studies. Int J Tuberc Lung Dis 2008;12:713-17.

3 Global Initiative for Chronic Obstructive Lung Disease. Global Strategy for the diagnosis, management, and prevention of chronic obstructive lung disease. Updated 2015. http://www.goldcopd.org/uploads/users/files/GOLD_Report_2015_ Apr2.pdf (last assessed 12 Jun 2015).

4 Chan-Yeung M, Lai CK, Chan KS, et al. The burden of lung disease in Hong Kong: a report from the Hong Kong Thoracic Society. Respirology 2008;13(Suppl 4): S133-65

5 Britton M. The burden of COPD in the UK: results from the Confronting COPD survey. Respir Med 2003;97(Suppl C):S71-9.

6 Seemungal TA, Donaldson GC, Paul EA, et al. Effect of exacerbation on quality of life in patients with chronic obstructive pulmonary disease. Am J Respir Crit Care Med 1998;157:1418-22

7 Donaldson GC, Seemungal T, Jeffries DJ, et al. Effect of temperature on lung function and symptoms in chronic obstructive pulmonary disease. Eur Respir $J$ 1999;13:844-9.

8 Davies L, Wilkinson M, Bonner S, et al. "Hospital at home" versus hospital care in patients with exacerbations of chronic obstructive pulmonary disease: prospective randomised controlled trial. BMJ 2000;321:1265-8.

9 Shepperd S, lliffe S. Hospital at home versus in-patient hospital care. Cochrane Database Syst Rev 2001;(3):CD000356.

10 Sridhar M, Taylor R, Dawson S, et al. A nurse led intermediate care package in patients who have been hospitalised with an acute exacerbation of chronic obstructive pulmonary disease. Thorax 2008;63:194-200.

11 Bourbeau J, Julien M, Maltais F, et al. Reduction of hospital utilization in patients with chronic obstructive pulmonary disease: a disease-specific self-management intervention. Arch Intern Med 2003:163:585-91.

12 Martin IR, McNamara D, Sutherland FR, et al. Care plans for acutely deteriorating COPD: a randomized controlled trial. Chron Respir Dis 2004;1:191-5.

13 Adams SG, Smith PK, Allan PF, et al. Systematic review of the chronic care model in chronic obstructive pulmonary disease prevention and management. Arch Intern Med 2007;167:551-61.

14 Littlejohns P, Baveystock CM, Parnell H, et al. Randomised controlled trial of the effectiveness of a respiratory health worker in reducing impairment, disability, and handicap due to chronic airflow limitation. Thorax 1991;46:559-64.

15 Cockcroft A, Bagnall P, Heslop A, et al. Controlled trial of respiratory health worker visiting patients with chronic respiratory disability. Br Med J (Clin Res Ed) 1987;294:225-8.

16 Pushparajah S, McClellan R, Henry A, et al. Use of a chronic disease management programme in COPD to reduce hospital admissions. Chron Respir Dis 2006:3:187-93

17 Kruis AL, Smidt N, Assendelft WJ, et al. Integrated disease management interventions for patients with chronic obstructive pulmonary disease. Cochrane Database Syst Rev 2013;10:CD009437.

18 Ko FW, Dai DL, Ngai J, et al. Effect of early pulmonary rehabilitation on health care utilization and health status in patients hospitalized with acute exacerbations of COPD. Respirology 2011;16:617-24.

19 Zwerink M, Brusse-Keizer M, van der Valk PD, et al. Self management for patients with chronic obstructive pulmonary disease. Cochrane Database Syst Rev 2014;3: CD002990.

20 Ko FW, Ngai JC, Ng SS, et al. COPD care programme can reduce readmissions and in-patient bed days. Respir Med 2014;108:1771-8.

21 Patel IS, Seemungal TA, Wilks M, et al. Relationship between bacterial colonisation and the frequency, character, and severity of COPD exacerbations. Thorax 2002;57:759-64.

22 Standardization of Spirometry, 1994 Update. American Thoracic Society. Am J Respir Crit Care Med 1995;152:1107-36.

23 Ip MS, Ko FW, Lau AC, et al. Updated spirometric reference values for adult Chinese in Hong Kong and implications on clinical utilization. Chest 2006;129:384-92.

24 Mahler DA, Wells CK. Evaluation of clinical methods for rating dyspnea. Chest 1988;93:580-6.

25 American Thoracic Society. ATS statement: guidelines for the six-minute walk test. Am J Respir Crit Care Med 2002;166:111-17.

26 Jones PW, Quirk FH, Baveystock CM, et al. A self-complete measure of health status for chronic airflow limitation. The St. George's Respiratory Questionnaire. Am Rev Respir Dis 1992;145:1321-7.

27 Jones PW. St. George's Respiratory Questionnaire: MCID. COPD 2005;2:75-9.

28 Casas A, Troosters T, Garcia-Aymerich J, et al. Integrated care prevents hospitalisations for exacerbations in COPD patients. Eur Respir J 2006;28:123-30.

29 Harrison SL, Janaudis-Ferreira T, Brooks D, et al. Self-management following an acute exacerbation of COPD: a systematic review. Chest 2015;147:646-61.

30 Puhan MA, Gimeno-Santos E, Scharplatz M, et al. Pulmonary rehabilitation following exacerbations of chronic obstructive pulmonary disease. Cochrane Database Syst Rev 2011;(10):CD005305.

31 National Institute for Health and Care Excellence. Chronic obstructive pulmonary disease in adults quality statement 5: Pulmonary rehabilitation after an acute 
exacerbation. Published date: July 2011. Last updated: February 2016. https://www. nice.org.uk/guidance/qs10/chapter/quality-statement-5-pulmonary-rehabilitationafter-an-acute-exacerbation (last assessed 23 Apr 2016).

32 Bolton CE, Bevan-Smith EF, Blakey JD, et al. British Thoracic Society guideline on pulmonary rehabilitation in adults. Thorax 2013;68(Suppl 2):ii1-30.

33 Spruit MA, Singh SJ, Garvey C, et al. An official American Thoracic Society/European Respiratory Society statement: key concepts and advances in pulmonary rehabilitation. Am J Respir Crit Care Med 2013;188:e13-64.

34 Harrison SL, Robertson N, Graham CD, et al. Can we identify patients with different illness schema following an acute exacerbation of COPD: a cluster analysis. Respir Med 2014;108:319-28.

35 Maddocks M, Kon SS, Singh SJ, et al. Rehabilitation following hospitalization in patients with COPD: can it reduce readmissions? Respirology 2015;20:395-404.

36 Nici L, Donner C, Wouters E, et al. American Thoracic Society/European Respiratory Society statement on pulmonary rehabilitation. Am J Respir Crit Care Med 2006;173:1390-413.

37 Tashkin DP. Long-acting anticholinergic use in chronic obstructive pulmonary disease: efficacy and safety. Curr Opin Pulm Med 2010;16:97-105.

38 Calverley PM, Anderson JA, Celli B, et al. Salmeterol and fluticasone propionate and survival in chronic obstructive pulmonary disease. $N$ Engl J Med 2007;356:775-89.
39 Kruis AL, Boland MR, Assendelft WJ, et al. Effectiveness of integrated disease management for primary care chronic obstructive pulmonary disease patients: results of cluster randomised trial. BMJ 2014;349:95392.

40 Fan VS, Gaziano JM, Lew R, et al. A comprehensive care management program to prevent chronic obstructive pulmonary disease hospitalizations: a randomized, controlled trial. Ann Intern Med 2012;156:673-83.

41 Jennings JH, Thavarajah K, Mendez MP, et al. Predischarge Bundle for Patients With Acute Exacerbations of COPD to Reduce Readmissions and ED Visits: A Randomized Controlled Trial. Chest 2015;147:1227-34.

42 National Institute for Health and Care Excellence. Chronic obstructive pulmonary disease in over 16s: diagnosis and management, NICE guidelines [CG101]. 2010. https://www.nice.org.uk/guidance/cg101 (last assessed 23 Apr 2016).

43 Yu WC, Tai EL, Fu SN, et al. Treatment of patients with chronic obstructive pulmonary disease as practised in a defined Hong Kong community: a cross-sectional pilot survey. Hong Kong Med J 2011;17:306-14.

44 Price $D$, West $D$, Brusselle $G$, et al. Management of COPD in the UK primary-care setting: an analysis of real-life prescribing patterns. Int J Chron Obstruct Pulmon Dis 2014;9:889-904.

45 Adamson SL, Burns J, Camp PG, et al. Impact of individualized care on readmissions after a hospitalization for acute exacerbation of COPD. Int J Chron Obstruct Pulmon Dis 2016;11:61-71. 